\title{
TRANS-AÇÕES DE GÉNERO, OPERANDO CONTRA O CISTEMA
}

A abrir este dossiê, recupero a ideia, dos primórdios dos estudos de género, nos tempos e textos de John Money (Money, Hampson e Hampson 1957): tentar criar à custa das pessoas trans* e intersexo uma teoria do género-cultura que se sobrepusesse ao sexo-natureza. A teoria de Money, que permitia organizar o dimorfismo sexual transformando-o em unidades discretas, no âmbito de um modelo de dois sexos (Laqueur 1990) que emerge com o Iluminismo e a crença da «Ciência» na «diferença sexual», é fundamental, como explica Paul B. Preciado (2018), para afirmar as potencialidades tecnológicas na dominação da natureza no âmbito da 2. a Guerra Mundial. Tecnogénero, pois. Mas também tecnosexo, se pensarmos nas possibilidades oferecidas pela tecnologia com as cirurgias de redesignação genital - possibilidade de progresso e de emancipação para alguns grupos, marca de opressão quando forçada, por critérios sobretudo estéticos do discurso biomédico para resolver o que para eles é genitália «ambígua» (Machado 2005) uso de hormonas, recurso a modos de tecnologicamente mediar o corpo de outra forma. Contudo, não é que o cisgénero - que se refere aos processos e experiência de género que coincide com o sexo atribuído (Vergueiro 2015) - não implique também tecnologias de género (Lauretis 1987), dado que a cisgeneridade é também mediada tecnologicamente com todo o arsenal de pílula contracetiva, maquilhagem, depilação a laser e a cera, moda, cabelos, indústria da cirurgia plástica e miríades de outras não fizessem parte de uma construção tecnológica, material e semiótica, do (cis)género. E como mostra Jack Halberstam (1998), encarar também as tecnologias de género (Lauretis 1987) que permitem uma performatividade que aparenta ser não performance na masculinidade, também das mulheres, como é o caso de determinadas roupas, sapatos, álcool, cigarros. Um corpo que é sempre produzido semiótica e materialmente em relações de poder, que nunca é simplesmente dado, tal como o género.

Falar apenas de homens e mulheres sem equacionar o plano dos usos queer do corpo, possibilidades mil de corpos intersexo e de corpos trans*, hibridizações

Departamento de Psicologia, Centro de Filosofia e Ciências Humanas - CFH, Universidade Federal de Santa Catarina - UFSC, Florianópolis, Brasil/Centro de Investigação e Intervenção Social do ISCTE-Instituto Universitário de Lisboa, Portugal.

Endereço postal: Centro de Filosofia e Ciências Humanas, Campus Universitário - Trindade, CEP 88.040-970 - Florianópolis, Santa Catarina - Brasil.

Endereço eletrónico: joao.m.oliveira@gmail.com 
e gender-bending implica não atender ao espectro vasto a que nos acostumámos a chamar género ou não entender o rizoma género (Oliveira 2016). Um género miríade e máquina de guerra e não apenas aparelho de Estado (Deleuze e Guattari 1987). Então é preciso pensar a partir das expressões de género trans* e não conformes às normas para conceptualizar o próprio género, habitualmente apenas entendido como cisgénero. Trata-se de um erro comum, uma sinédoque de género, tornar o todo (género) pela parte (cisgénero), em muito material produzido sobre género, não entender que se está sempre a falar ou a pressupor cisgénero, bio-homens e bio-mulheres (Preciado 2003). Então, um dos primeiros efeitos desta sinédoque será que não incorporar ou pensar o género como também transgénero equivale a fazer uma espécie de ciscentrismo, a que Vergueiro (2015) chama o cistema (sistema cis), em que só pessoas cisgénero contam como propriamente e autenticamente marcadas pelo género. Infelizmente, a maioria da pesquisa sobre género, sobretudo a que documenta exaustivamente diferenças entre homens e mulheres, é na realidade sobre homens e mulheres cis. O género é expressão e norma simultaneamente, poder, potestade e potência (J. M. Oliveira 2016). Recorremos à ideia de trans*, esboçada por Lucas Platero (2014), como um conceito amplo para incluir identificações, identidades e expressões de género transexuais, transgénero e trans, travesti, etc., pensadas de forma heterogénea, multíplice e não forçosamente adstritas ao binarismo de sexo e de género. Então este trans* é um signo de multiplicidade que percorre todo o espectro do género: um trans* que inclui simultaneamente as especificidades trans* (travestis no contexto latino-americano, transgénero, transexuais, entre outras) mas também outras formas de se colocar para lá do binarismo de género (genderfuck, genderqueer, queer, não binárias, entre outras).

Levando esta definição a sério, precisamos simultaneamente atender às especificidades dos corpos lidos/inteligíveis como trans* e universalizar o ponto de vista trans* para pensar outros modos não só de teorizar o género, mas sobretudo de o problematizar a partir desta perspetiva, vendo no género e nas teorias sobre o género saberes que são sempre e desde logo saberes trans, que são desde logo práxis e ação sobre o mundo - trans-ação. Neste dossiê estamos muito interessadas em discutir e entender saberes trans como práticas, trans-ações no duplo sentido de ação trans e de transação, de troca com outros saberes. Então este dossiê assume como ética a despatologização dos saberes, identificações e corpos trans*: não será a biomedicina a definir quem conta como trans* e quem não conta, não serão os saberes psi a definir trans* como doente e cis como normal. Não há expressões de género (em si mesmo) patológicas.

A despatologização dos corpos trans* implica a descolonização dos corpos destes critérios de quem pode contar como humano (Haraway 2004): implica que possamos pensar corpos e pessoas para lá da cisnormatividade, que, como mostra Viviane Vergueiro (2015), se trata de um aparato normativo que produz uma ideia do género como pré-discursivo, binário e estável ao longo da vida. A pré-discursi- 
vidade está muito associada a uma certa metafísica da substância descrita por Judith Butler (2017), um género verificável por especialistas nos saberes que definem o que é sexo e o que é género, como uma unidade discreta e identificável e que se exprime na ideia da irredutibilidade do sexo biológico como verdade interior e alinhado com o género. Pouco atento às múltiplas possibilidades quer de desobediência, quer de ressignifcação da norma, este género seria a expressão dessa ontologia, o sexo (Oliveira 2017). Contudo, os trabalhos da biologia (Fausto-Sterling 2012), da filosofia (Butler 2017) e da história (Laqueur 1990) desconstroem totalmente esta premissa, mostrando como a inteligibilidade das normas de género vai dar sentido e produzir o sexo. Este discurso da precedência e causalidade do sexo sobre o género fundamenta também a explicação biomédica da transexualidade, denunciada por Sandy Stone (2006), como discurso do corpo errado, de um corpo que tem que ser tecnologicamente corrigido para apresentar uma coerência com uma identificação de género tratada como identidade e que dá sentido patologizante à experiência trans*, traduzida em vária nosologia psiquiátrica e diagnóstico médico (ver Davy 2015) que varia entre perturbação da identidade de género e disforia de género. A mesma Sandy Stone sofreu o ataque de feministas transfóbicas, como Janice Raymond (descrito em Oliveira 2014), ataque esse que, infelizmente, ainda hoje continua a ser desferido pelas feministas essencialistas que destratam as mulheres trans* (designações assentes em critérios de autodeterminação de género) como não mulheres, os homens trans* como mulheres traidoras e encaram ambxs como uma ameaça do patriarcado, tomando transfobia por feminismo. Sandy Stone (2006) transformou esse ataque em teoria trans*, produzindo uma nova forma e posição para pensar as pessoas trans ${ }^{*}$, nomeadamente ao demonstrar a importância da heteroglossia do género e salientar a pluralidade de experiências e de socializações de género. Assim, o já gasto argumento essencialista da socialização e da experiência feminina (como se não fosse uma multiplicidade) tenta produzir o efeito que diz descrever: manter o género fixo num binário como se ele fosse apenas cisgénero e permanentemente fixo. Essa fixidez do género é um exercício (de ficção) para manter seguras, naturalizadas e policiadas as fronteiras de género. Se pensarmos no transfeminícidio (Bento 2016) e nas necropolíticas trans (Oliveira 2014), vemos o efeito destas normas no homicídio muito acima dos padrões para outras populações (overkill), esperança média de vida muito mais baixa para esta população, a violência policial e de Estado e o noticiar destas mortes a partir das mesmas premissas transfóbicas que certos tipos de feminismo compartilham, nomeadamente pela sua crença na fixidez e constância do género, metafísica da substância e ontologia estática do dimorfismo de género (Butler 2004). É preciso questionar estas formas de violência e a sua legitimação em alguma da teoria e práxis feministas.

Nos últimos anos, para além do surgimento de inúmeras obras e periódicos como o Transgender Studies Quarterly, a reflexão e a análise da posição das pessoas trans* e intersexo é uma das áreas mais vibrantes da investigação e intervenção 
feminista atualmente. Desde os tempos do manifesto de Sandy Stone (2006), inicialmente publicado em 1987 passando pela publicação dos Transgender Studies Readers, já com uma segunda edição (Stryker e Azura 2013), no panorama anglo-saxónico, estas áreas, denominadas também de teoria trans (Stryker 2006), têm sido bastante pensadas e transpostas para políticas públicas. Um outro desenvolvimento é o transfeminismo. No Brasil, é editada a antologia Transfeminismo (Jesus 2014) que atesta a crescente importância da inter-relação entre teoria trans ${ }^{*}$ e teoria feminista. Esta inter-relação também é um modo eficaz de rebater determinados fantasmas de formas culturais de feminismos radicais minoritários e sectários que tentam ressurgir. Como resposta, Susan Stryker (2015) recupera a figura de Frankenstein para pensar-se também como monstro, usando a estratégia da Queer Nation, de usar o insulto como identificação, desarticulando-o do seu propósito de discurso de ódio e ressignificando-o (Butler 1993). A recusa do projeto eurocêntrico de um humanismo que o feminismo cultural cultuou, a partir de uma ideia de mulher essencial a que as mulheres trans* não podiam aspirar a ser, implicou uma série de respostas e de posicionamentos, vários deles traduzidos na antologia Políticas Trans (Galofre e Missé 2015).

Outras alternativas ao cistema de produção de conhecimento incluem a importante consideração de pessoas trans* que possam falar sobre pessoas trans*. Vou dar alguns exemplos, sem nenhuma pretensão de exaustividade. O trabalho de Megg R. Gomes de Oliveira (2017) mostra a importância de produzir saberes interseccionais que cruzem cisnormatividade, heteronormatividade e raça para pensar a resistência e existência de gays e bichas negras na educação, permitindo pensar as possibilidades de cruzamento de eixos de opressão e privilégio, mas também as potências da resistência a esses mesmos eixos. Igualmente o trabalho de Luma Nogueira de Andrade (2012) desmontou a questão do abandono escolar de pessoas travestis, mostrando que a escola é hostil à presença de trans ${ }^{*}$ nos seus espaços. A recente tese de doutoramento de Adriana Sales (2018) cartografa as lideranças do movimento travesti no Brasil, apresentando-se na confluência de um saber construído por uma travesti sobre o movimento travesti. No campo do trabalho sexual, o livro de Amara Moira (2016) mostra as múltiplas interseções entre trabalho sexual e travestilidade.

Estas são exemplos de investigações que não tomam as pessoas trans* ${ }^{*}$ como objeto de estudo como fazem muitos investigadorxs cis, mas a construção de pesquisa trans* e travesti feita por pessoas trans* e travestis. Trata-se de projetos de insurreição de saberes acompanhados também pela entrada das pessoas trans* na academia, «Nada de nós sem nós», diria o movimento trans*. Sem com isto negar o que pessoas trans* também contribuíram para pensar essa condição cis e a cisnormatividade, como já mencionámos. Então, neste dossiê, quisemos coligir trabalhos para tentar pensar uma ideia de teoria (feminista) trans que não tome as pessoas trans* como objeto de estudo, mas antes construa saberes com elas e a partir delas. 
Os artigos apresentados dão conta do grande progresso desta investigação, cada vez mais marcada pela interseção de identificações e posições sociais, mas também pela interdisciplinaridade na pesquisa, muitas vezes marcada pela aliança com o ativismo como forma de usar a investigação para produzir alguns efeitos na vida das pessoas trans* e não binárias. O texto de Tiago Coacci, baseado no Brasil, é um bom exemplo de um trabalho em que se interrogam as fontes científicas do direito para produzir quem conta para a Lei como sujeito transexual. Analisando a transição de um modelo patologizador para um direito que recorre mais à autodeterminação, via despatologização, o texto oferece um panorama do modo como direito e ciências biomédicas e psi se retroalimentam e de que forma vão produzir determinados sujeitos jurídicos. Em Portugal, Ana Cristina Santos conceptualiza o cuidado como ato heroico, a partir de uma releitura das narrativas de pessoas trans ${ }^{*}$ e não binárias e da forma como se constroem redes de cuidados, onde família e Estado social falham na proteção contra a precarização, na Europa do Sul.

Sobre o Equador, a estratégia de Fernando Sanchéz e R. Lucas Platero é recorrer e recontar memórias trans* como ato político. Para tal oferecem-nos uma história de como o movimento trans no Equador se adaptou e lutou dentro de um determinado contexto socio-histórico e político. Trazendo saberes-lutas construídos fora do Norte global e mostrando como as pessoas envolvidas nestas lutas são marcadas socialmente, racializadas e precarizadas para além do género, este texto é muito significativo na construção de saberes trans* que contam os modos como se vivenciaram as lutas naquele país latino-americano. Já no trabalho de Mar Fournier Pereira, a partir da Costa Rica, um grupo de mulheres trans* trabalhadoras e ex-trabalhadoras do sexo discutem as formas como lidaram com a extrema violência da polícia, do sistema de saúde, da lei, das ciências sobre si e o modo como produziram resistência face a um Estado que as reprimia de várias formas, recorrendo inclusivamente à violação. Uma pedagogia da crueldade que é retratada assim pelas experiências destas mulheres. Estas experiências não se limitam no entanto à violência. A pesquisa de André Leite e de Claudiene Santos (Brasil) sobre os modos não esperados pelas ciências biomédicas de como mulheres trans* recorrem a um discurso místico sobre a terapia hormonal mostra como as hormonas devem ser pensadas enquanto agentes sociais e políticos de direito próprio. As hormonas são aqui consideradas a partir da teoria queer e provocam uma reflexão sobre o papel das tecnologias nas subjetivações de género. No caso do trabalho de Claudenilson Dias e de Leandro Colling sobre pessoas trans* nas religiões afro-brasileiras, mostram-se as resistências e as tensões com que estas pessoas podem ser recebidas em terreiros de Candomblé. Igualmente se salientam os modos que as pessoas trans* encontram para ultrapassar essa situação, para além das invisibilidades produzidas e da transfobia. Os dois últimos trabalhos versam sobre pessoas não binárias. No caso de Espanha, Isabel Goméz e Lucas Platero trazem-nos um olhar sobre quem está fora da inteligibilidade do binarismo de género. Como afirmam, trata-se de um processo de construção de subjetividades em curso mas 
que já implica uma diversidade de posições e de ruturas com as categorias sociais e expetativas sociais. A partir de Portugal, Teresa Teixeira e Nuno Santos Carneiro mostram como pessoas não binárias, ao desconstruírem com os seus corpos as normas de género, são encaradas como menos humanas ou não humanas pela relação entre género, reconhecimento e inteligibilidade do humano. As implicações na escuta destas pessoas são analisadas, explorando a ambiguidade e fluidez de género, com recurso a questionamento, desnaturalização e incerteza próprios da teoria queer.

Conforme explica Susan Stryker (2006), estes saberes produzidos a partir da experiência das pessoas trans* foram saberes lidos como marginais e irrelevantes. A teoria trans vai promover a insurreição dos saberes subjugados como lhe irá chamar Michel Foucault (1980). Aqui Foucault refere-se à produção de saberes desqualificados, que contam pouco na hierarquia dos saberes, que estão abaixo do reconhecimento. Como exemplos, os saberes das mulheres, queer e trans*, saberes decoloniais e pós-coloniais, dos quilombos e dos movimentos sociais. Os efeitos de uma política de despatologização das suas subjetividades que resultam de lutas dos movimentos sociais e de uma crescente participação e esforço das pessoas trans* em estarem presentes, recontando histórias que foram feitas sem elas, como mostram, por exemplo, na sua fundamental participação nos motins de Stonewall (Rivera e Johnson 2015) e da Compton Cafeteria em S. Francisco em 1966 (Stryker 2008), entre muitos outros, ilustram a necessidade de contar uma história que não seja a repetição da invisibilidade e exclusão das pessoas trans*. A (cis)-história parece ser sempre a história do cistema. Essa desocultação corresponde também a um processo de dessubjugação dos saberes, que vai acompanhar os avanços legais que permitem passar de um modelo de identidade de género atestada medicamente para um modelo de autodeterminação de género. Graças aos esforços das campanhas pela despatologização trans * que grande parte do movimento LGBT só irá abraçar bem mais tarde - dada a dificuldade de determinados movimentos sociais homonormativos mainstream e feminismos essencialistas, com práticas transfóbicas legitimadas num modelo patologizador -, conseguiu-se transpor na lei em países como Argentina, Dinamarca, Malta, Noruega, Irlanda e Portugal a autodeterminação de género. Assim, nestes países não existe uma mediação médica ou psi para determinar quem pode solicitar o reconhecimento legal da sua autodeterminação de género. Estes saberes são parte fundamental desta luta e de uma crescente preocupação com pessoas variantes de género, como as pessoas não binárias, com o espectro do género para lá do binarismo e numa luta para que os saberes delas constituam outros léxicos, outros vocabulários tanto para a teoria feminista como para os estudos de género. É preciso pensar também nas consequências de políticas dos movimentos sociais sempre centrados num modelo de democracia liberal, numa lógica estritamente identitarista e reformista de reivindicação de direitos, sem tomar em consideração as formas de violência administrativa e a cumplicidade do Estado com determinadas formas de necropolítica trans, 
racial e de género (Spade 2015). Uma política trans não pode deixar de analisar as interseções com outros eixos de dominação em que as vidas das pessoas trans* e pessoas variantes de género também se jogam. Então um olhar mais complexo e muito para lá da retórica comum dos direitos coloca desafios que aqui tentamos também descrever. Este dossiê imagina-se como uma pequena contribuição para o esforço de dessubjugação dos saberes trans, tentando traçar os rastros das ações trans contra o cistema.

\section{Referências bibliográficas}

Andrade, Luma Nogueira. 2012. Travestis na Escola: assujeitamento e resistência à ordem normativa. Tese de doutorado. Fortaleza: Universidade Federal do Ceará.

Bento, Berenice. 2016. «Transfeminicídio: violência de gênero e o gênero da violência». In Dissidências sexuais e de gênero, organizado por Leandro Colling, 25-40. Salvador: EDUFBA.

Butler, Judith. 1993. Bodies that matter: on the discursive limits of 'sex'. New York: Routledge. Butler, Judith. 2004. Undoing gender. New York: Routledge.

Butler, Judith. 2017. Problemas de Gênero: Feminismo e subversão da identidade. Lisboa: Orfeu Negro.

Davy, Zowie. 2015. «The DSM 5 and the politics of diagnosing transpeople». Archives of Sexual Behavior 44: 1165-1176. DOI: https://doi.org/10.1007/s10508-015-0573-6

Deleuze, Gilles, e Felix Guattari. 1987. A thousand plateaus. Minneapolis, MN: Minnesota University Press.

Fausto-Sterling, Anne. 2012. Sex/Gender: Biology in a Social World. New York: Routledge.

Foucault, Michel. 1980. «Two Lectures». Power/Knowledge, organizado por Colin Gordon, 78-108. New York: Pantheon Books,

Galofre, Pol, e Miquel Missé. 2015. Politicas Trans: una antologia de textos desde los estudios trans norteamericanos. Barcelona: Equales.

Gomes de Oliveira, Megg Rayara. 2017. O diabo em forma de gente: (R)existências de gays afeminados, viados e bichas pretas na educação. Curitiba: Prismas.

Halberstam, Jack. 1998. Female masculinity. Durham: Duke University Press.

Haraway, Donna. 2004. «Otherworldly conversations: terrain topics, local terms». In The Haraway Reader, organizado por Donna Haraway, 120-150. London: Routledge.

Jesus, Jaqueline G. 2014. Transfeminismo: teorias e práticas. São Paulo: Metanóia.

Laqueur, Thomas. 1990. Making Sex: Body and Gender from the Greeks to Freud. Cambridge: Harvard University Press.

Lauretis, Teresa. 1987. Technologies of Gender. Bloomington: Indiana University Press.

Machado, Paula Sandrine. 2005. «O sexo dos anjos: um olhar sobre a anatomia e a produção do sexo (como se fosse) natural». Cadernos Pagu 24: 249-281.

Moira, Amara. 2016. E se eu fosse puta? São Paulo: Hoo.

Money, John, John Hampson, e Joan Hampson. 1957. «Imprinting and the establishment of gender role». Archives of Neurology and Psychiatry 77, 333-336.

Oliveira, João Manuel de. 2014. «A necropolítica e as sombras na teoria feminista». ex aequo 29: 69-82.

Oliveira, João Manuel de. 2016. «Trânsitos de Género: leituras queer/trans* da potência do rizoma género». In Dissidências sexuais e de gênero, organizado por Leandro Colling, 109-132. Salvador: EDUFBA. 
Oliveira, João Manuel de. 2017. Desobediências de género. Salvador: Devires.

Platero, Lucas. 2014. Trans*exualidades: Acompañamiento, factores de salud y recursos educativos. Barcelona: Bellaterra.

Preciado, Paul B. 2002. Manifiesto Contrasexual. Madrid: Opera Prima.

Preciado, Paul B. 2018. Testo Junkie. São Paulo: N-1.

Rivera, Sylvia, e Martha Johnson. 2015. Acción Travesti Callejera Revolucionária. Madrid: editorial imperdible.

Sales, Adriana. 2018. Travestis brasileiras e escolas (da vida): cartografias do movimento social organizado aos gêneros nômades. Tese de doutorado. Assis: Universidade Estadual Paulista.

Spade, Dean. 2015. A normal life: Administrative Violence, Critical Trans Politics, and the Limits of Law. Durham, NC: Duke University Press.

Stone, Sandy. 2006. «The empire strikes back: a posttranssexual manifesto». In The transgender studies reader, organizado por Susan Stryker e Stephen Whittle, 221-235. New York: Routledge.

Stryker, Susan. 2006. «(De)subjugated knowledge: an introduction to transgender studies», The Transgender Studies Reader, organizado por Susan Stryker e Stephen Whittle, 1-17. New York: Routledge.

Stryker, Susan. 2008. Transgender history. Berkeley, CA: Seal Press.

Stryker, Susan. 2015. «Mis palabras a Victor Frankenstein sobre el Pueblo de Chamonix: performando la ira transgénero». In Políticas Trans: una antología de textos desde los estudios trans norteamericanos, organizado por Pol Galofre e Miquel Missé, 135-165. Barcelona: Equales.

Stryker, Susan, e Airen Z. Azura. 2013. The Transgender Studies Reader 2. New York: Routledge.

Vergueiro, Viviane. 2015. Por inflexões decoloniais de corpos e identidades de gênero inconformes: uma análise autoetnográfica da cisgeneridade como normatividade. Dissertação de mestrado. Salvador: Universidade Federal da Bahia.

João Manuel de Oliveira. Professor Visitante Associado na Universidade Federal de Santa Catarina, Brasil. Trabalha na área dos Estudos de Género, Estudos Críticos da Sexualidade, Teoria Feminista e Teoria Queer. Doutor em Psicologia Social. Investigador no Centro de Investigação e de Intervenção Social do Instituto Universitário de Lisboa.

Endereço eletrónico: joao.m.oliveira@gmail.com 